\title{
Flowability of powders for selective laser sintering (SLS) investigated by round robin test
}

\section{Conference Paper}

\section{Author(s):}

Schmid, Manfred; Amado, Felipe; Levy, Gideon; Wegener, Konrad

Publication date:

2014

Permanent link:

https://doi.org/10.3929/ethz-a-010057806

Rights / license:

In Copyright - Non-Commercial Use Permitted 


\title{
Flowability of Powders for Selective Laser Sintering (SLS) investigated by Round Robin Test
}

\author{
M. Schmid \& F. Amado \\ Inspire AG, irpd, 9014 St. Gallen, Switzerland \\ G. Levy \\ IPL, CDRsp, 2411-901 Leiria, Portugal \\ K. Wegener \\ ETH Zürich, IWF, 8092 Zürich, Switzerland
}

\begin{abstract}
Compacting and consolidation behaviour of SLS powders under motion and agitation plays an important role during SLS processing. Powder density, part density and finally the mechanical properties of the finished SLS goods are influenced from the flow characteristics of powders during movement. The paper presents a simple access to measure powder flowability by determining the bulk- and tap-density (Hausner ratio) and indicates their significance by an interlaboratory test. With this very simple approach the flowability of virgin and aged SLS powders can be unambiguously distinguished.
\end{abstract}

\section{INTRODUCTION}

\subsection{Additive Manufacturing (AM) / Selective Laser Sintering (SLS)}

Additive Manufacturing (AM) is a computerized process for direct transformation of 3D CAD data into physical objects by a variety of different approaches (Gibson 2010). Selective Laser Sintering (SLS) of plastic powders is part of these 'layer by layer' based additive production techniques that are repeatedly considered as the next industrial revolution (Hopkinson 2006). Solidifying plastic powders with laser radiation by means of digital data opens countless options for production of individualized parts with great freedom of complexity (Kruth 2007). However, the development of new polymer powders suitable for SLS process is complex as a lot of different materials properties have to be fulfilled concurrently. Figure 1 summarizes five main factors in this connection: powder and particle as well as optical, thermal and rheological behaviour.

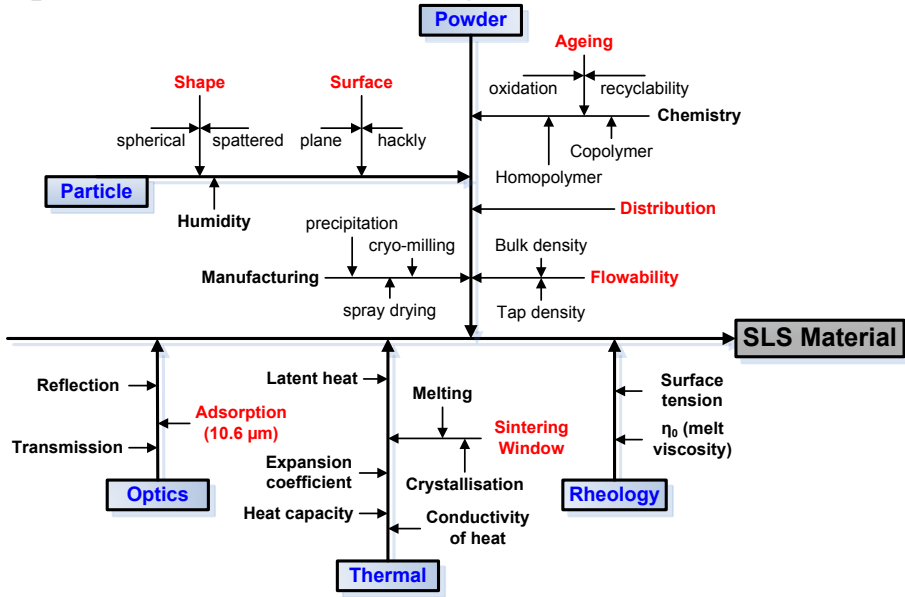

Figure 1. Influence Parameter on SLS powders
Whether a polymer powder is appropriate for SLS processing cannot be anticipated completely by analytical approach. It must be investigated by trial and error on commercial SLS equipment as well. However powder analyses regarding the main features (red titel in Figure 1) can deliver valuable information as a developing basis to achieve new and successful SLS powders on a reduced time frame (Wendel 2008, Drummer 2010, Schmid 2011).

The present investigation focus on the compacting and consolidation behaviour of SLS powders under motion and intensive agitation as it is the case during powder distribution by roller (3D-systems) or blade spreading (EOS) in commercial SLS systems. The ability of powders to generate a certain density (packing) under these conditions of turbulences is reflected in the density of SLS parts and finally in their mechanical properties. Thus the powder flowability is an important and not negligible parameter during development process.

\subsection{Flowability of powders}

The efforts to predict the behavior of SLS powders during spreading and distribution in SLS equipment increases as this performance is recognized as a critical parameter for density of powder and parts (Amado 2011, Rietzel 2011, Ziegelmeier 2013).

Many techniques are available to characterize the flow properties of powders. Krantz 2009 provide a comprehensive description of different techniques, considering static and dynamic powder state conditions. Table 1 gives an overview of the most common techniques in use, particularly in the food and pharmaceutical industry. 
Table 1. Most common powder characterization methods

\begin{tabular}{|l|l|l|l|}
\hline \multicolumn{2}{|c|}{ Method } & Condition & Report \\
\hline $\begin{array}{l}\text { Bed } \\
\text { Ratio }\end{array}$ & $\begin{array}{l}\text { Dynamic } \\
\text { under vertical } \\
\text { fluid drag } \\
\text { load }\end{array}$ & $\begin{array}{l}\text { Fluidized height } \\
\text { v/s upstream } \\
\text { fluid flow }\end{array}$ \\
\hline $\begin{array}{l}\text { Angle of } \\
\text { repose } \\
\text { DIN ISO 4324 }\end{array}$ & $\begin{array}{l}\text { Static under } \\
\text { free external } \\
\text { load }\end{array}$ & Pile angle \\
\hline $\begin{array}{l}\text { Ring Shear } \\
\text { Cell } \\
\text { ASTM D 6773 }\end{array}$ & $\begin{array}{l}\text { Quasi-Static } \\
\text { under } \\
\text { pressure }\end{array}$ & $\begin{array}{l}\text { Shear force v/s } \\
\text { normal pres- } \\
\text { sure/compres- } \\
\text { sion rate }\end{array}$ \\
\hline $\begin{array}{l}\text { Revolution } \\
\text { Powder } \\
\text { Analyzer }\end{array}$ & $-=\begin{array}{l}\text { Dynamic } \\
\text { under } \\
\text { rotation }\end{array}$ & $\begin{array}{l}\text { Avalanche angle } \\
\text { /Surface fractal; } \\
\text { Fluidisation }\end{array}$ \\
\hline $\begin{array}{l}\text { Bulk/Tap } \\
\text { Density } \\
\text { ASTM D 7481 }\end{array}$ & $\begin{array}{l}\text { Static under } \\
\text { the effect of } \\
\text { powder } \\
\text { weight }\end{array}$ & $\begin{array}{l}\text { Loose and } \\
\text { packed height } \\
\text { v/s n }{ }^{\circ} \text { of taps } \\
\text { (Hausner Ratio) }\end{array}$ \\
\hline
\end{tabular}

It is well known that results provided by each method are strongly dependent upon the powder stress condition. Techniques that reflect an aired state as the bed expansion ratio are appropriate to predict the fluidization performance, while methods with externally charged and compacted powder give a suggestion about static stability and compressibility ratio. Some of these methods are easy to access and can be simply accomplished (Angle of repose/ Bulk \& Tap density). Others need higher sophisticated apparatus and corresponding investments (Ring Shear Cell, RPA). However, presently no specific method has been established for SLS powders. It is not completely clear which one of these methods provides reliable analytical data for SLS powders currently.

In order to reveal the viability of an analytical method for a certain measuring problem regarding repeatability and reproducibility it is a common procedure to perform 'Round Robin Tests' (Interlaboratory comparison).

\subsection{Round Robin Test / Interlaboratory Comparison}

A key problem of almost any analytical method is their validation (Ellison, 2000). One possibility to realize a validation is to execute or participate in Round Robin Tests or Interlaboratory Comparisons (Mandel, 1991). Data, generated from different laboratories on the same sample, afford a lot of valuable information regarding the standard deviation of repeatability and reproducibility of the certain analytical method. The most important factors produce deviations between individual measured results are:

a) the operator, b) the equipment and the analytical instruments, c) the calibration of the equipment and the instruments and d) the environmental effects during the test procedure, i.e. influence of temperature, humidity, light, pollution, etcetera.
The factors mentioned above are mathematically described by calculating the main characteristic interlaboratory results:

- the robust standard deviation of repeatability $\mathbf{s}_{\mathbf{r}}$ (factors a), b), c) and d) are identical;

\section{$\rightarrow$ repeatability conditions;}

- the robust standard deviation of reproducibility $\mathbf{S}_{\mathbf{R}}$ (factors a), b), c) and d) are varied; $\rightarrow$ reproducibility conditions.

The source and the significance of these terms used in Round Robin Tests are defined in Figure 2 and are further explained by Affolter, 2001.

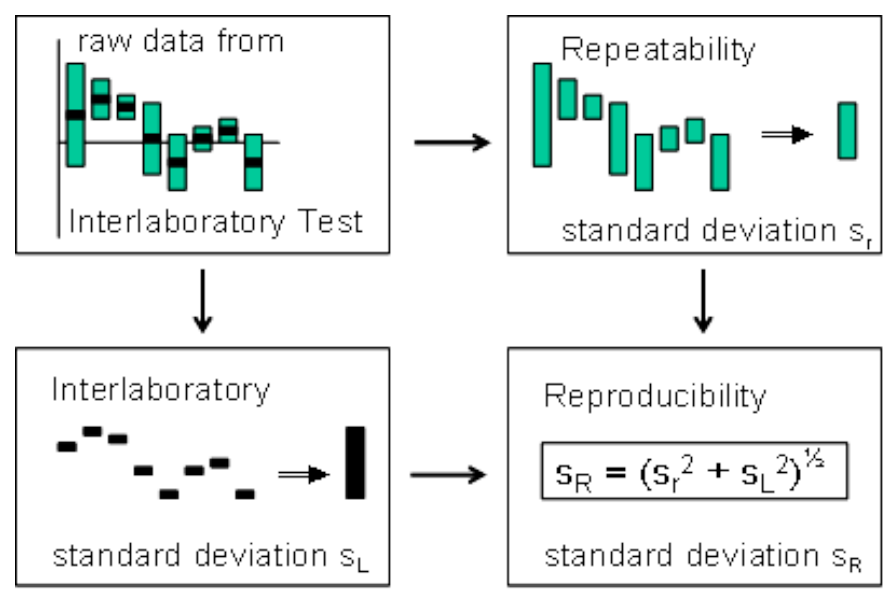

Figure 2. Correlation between statistical terms $\left(\mathrm{s}_{\mathrm{r}}, \mathrm{s}_{\mathrm{L}}\right.$ and $\left.\mathrm{s}_{\mathrm{R}}\right)$.

The calculations of the presented Round Robin Test are base upon robust statistics as defined in DIN 38402-45. The standard deviations $\left(\mathrm{s}_{\mathrm{r}}, \mathrm{s}_{\mathrm{R}}\right)$ are calculated iterative. The closer the measured values are at the calculated mean value the higher their weighting. Regarding this statistical model also the mean value (called: 'Hampel estimator') is achieved by iterative calculation. Robust statistics with iterative calculated indicators are of high steadiness as no outlier must be removed during computations and all measured valueas of all Round Robin Test participants will be incorporated into the results.

\section{HAUSNER RATIO - ROUND ROBIN TEST}

\subsection{Determination of Hausner Ratio (HR)}

The ratio of tap and bulk density provide a statement on the flowability of powders and is called 'Hausner Ratio (HR)'. The following powder classification regarding HR is described from Barbosa-Canovas, 2005.

- $\quad$ HR $<1.25$ high powder flowability

- $1.25<\mathrm{HR}<1.4$ decreased powder flowability

- HR > 1.4 cohesive powder

SLS powders should be typically under a limit of 1.25 (high flowability) to be regarded as a useful powder with sufficient powder density. 
Tap densities are typically obtained with a simple laboratory vibration tamper where an excenter is used for periodical compaction moves (see Table 1). In the present Round Robin Test this concept is even more simplyfied, as not every participant possesses a respective apparatus defined in ASTM D7481. Thus, for the determination of the Hausner factor in this study, only two laboratory elements are required: a plastic measuring cylinder with a volume of $100 \mathrm{ml}$ and a powder funnel (orifice must match the graduated cylinder) (see Figure 3).

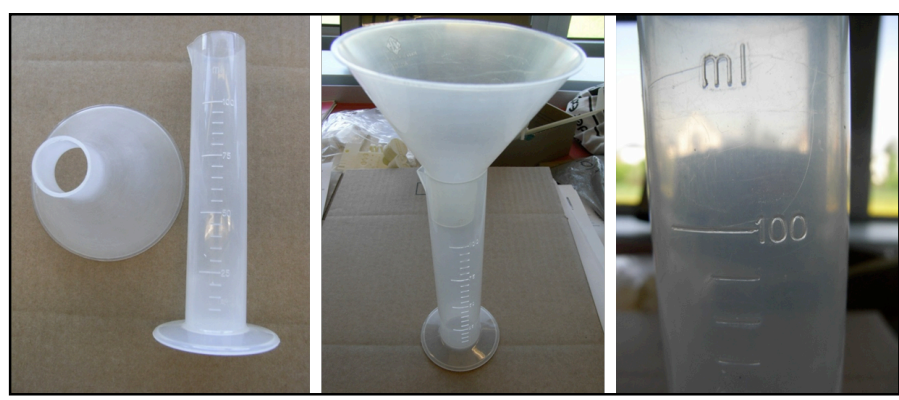

Figure 3. Necessary lab equipment for determination of HR

In total 9 qualified SLS laboratories with sufficient experience in handling SLS powders take part in the Interlaboratory comparison. In order to achieve reliable and compareable information the participant have to adhere to the following instructions strictly:

- Determination of the weight of a $100 \mathrm{ml}$ plastic measuring cylinder $\left(\mathrm{m}_{0}\right)$. Accuracy of the balance should be at least $0.1 \mathrm{~g}$.

- Fill in the graduated cylinder from a height of approximately $5 \mathrm{~cm}$ above the funnel with the experimental powder by pouring it loosely until the 100 $\mathrm{ml}$ mark is reached without any mechanical compaction.

- Determination of the total weight (cylinder + powder) $\left(\mathrm{m}_{1}\right)$.

- Compaction of the powder in the cylinder by hand tapping on a hard surface (table) with low power; a frequency of approximately $0.5 \mathrm{~Hz}$, and a duration of $2 \mathrm{~min}$.

- Determination of preliminary tapped volume $\left(\mathrm{V}_{\mathrm{St}}\right)$.

- Further tapping of the powder for $1 \mathrm{~min}$ and redetermination of the compacted volume $\left(\mathrm{V}_{\mathrm{St}}\right)$.

- Tapping for a minute and repeat until $\mathrm{V}_{\mathrm{St}}$ is constant (about 1-2 ml exactly).

- Calculate the HR value following Equation 1:

$$
\begin{aligned}
& \mathrm{HR}=\left[\left(\mathrm{m}_{1}-\mathrm{m}_{0}\right) \text { in } \mathrm{g} / \mathrm{V}_{\mathrm{St}} \mathrm{ml}\right] /\left[\left(\mathrm{m}_{1}-\mathrm{m}_{0}\right) \text { in } \mathrm{g}\right. \\
& / 100 \mathrm{ml}]=100 \mathrm{ml} / \mathrm{V}_{\mathrm{St}}
\end{aligned}
$$

- This procedure should be repeated $3 x$ for each powder (each done with a new powder sample).

\subsection{SLS powder material for HR determination}

In this Round Robin study, the following materials are considered to be tested with the described method:

- Duraform DF - virgin powder

- Duraform DF - used powder

- PA 2200 - virgin powder

- irpd research powder - improved flowability

The aging status of the powders was characterised by Melt Volum Rate (MVR) measurements (see Table 2). All powder materials were provided by inspire AG, irpd (350 $\mathrm{ml}$ per sample) in order to be sure that every participant uses the same powder. Each sample has to be measured tree times by each contributor. All results were collected by inspire $\mathrm{AG}$, irpd and evalated regarding the described statistics (chapter 1.3).

\subsection{HR Results}

The following results (Table 2, Figure 4, 5, 6 and 7) were obtained by statistical calculation (DIN 3840245 ) of the single results of the 9 participants. All involved laboratories remain anonymous and are encoded from number 1 to 9 . Table 2 summarizes the main statistical values for the 4 powder samples.

Table 2. Summary of the HR result obtained by Round Robin

\begin{tabular}{lccccc}
\hline Material & MVR & & \multicolumn{3}{c}{ HR Test Results } \\
\cline { 2 - 2 } \cline { 5 - 6 } & $\mathrm{g} / 10 \mathrm{~min}$ & & Hampel & $\mathrm{S}_{\mathrm{r}}$ & $\mathrm{S}_{\mathrm{R}}$ \\
\hline DF virgin & $>70$ & & 1.148 & 0.006 & 0.028 \\
DF used & $<15$ & & 1.225 & 0.008 & 0.023 \\
PA 2200 virgin & $>60$ & & 1.185 & 0.008 & 0.025 \\
Irpd R-powder & ---- & & 1.116 & 0.004 & 0.048 \\
\hline
\end{tabular}

Figure 4, 5, 6 and 7 depicts the laboratory results in comparison to each other. The calculated mean value ('Hampel estimator') is given in the Figures as well as the range of $\pm 2 * \mathrm{~S}_{\mathrm{R}}$ (doted line). The limit of $\pm 2{ }^{*} \mathrm{~S}_{\mathrm{R}}$ is used as a confidence interval. If the results of a participant are within this limit it can be regarded as 'good result' fully in acordance with the Round Robin Test expectations.

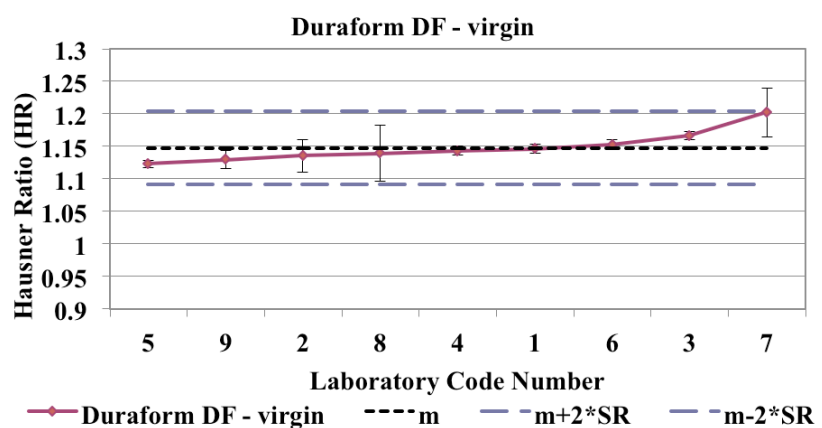

Figure 4. Summary of results of 9 labs for Duraform DF virgin 


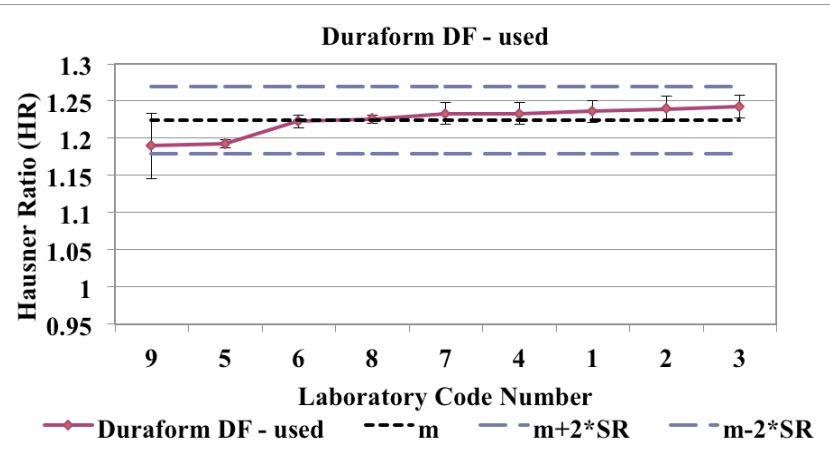

Figure 5. Summary of results of 9 labs for Duraform DF used

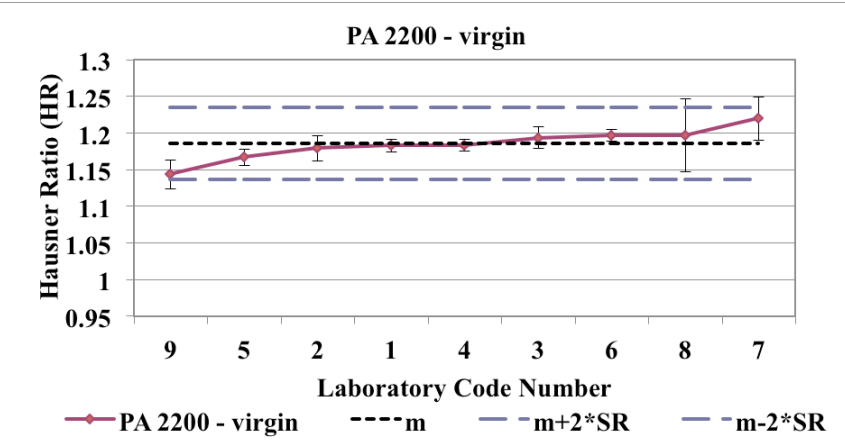

Figure 6. Summary of results of 9 labs for PA 2200 virgin

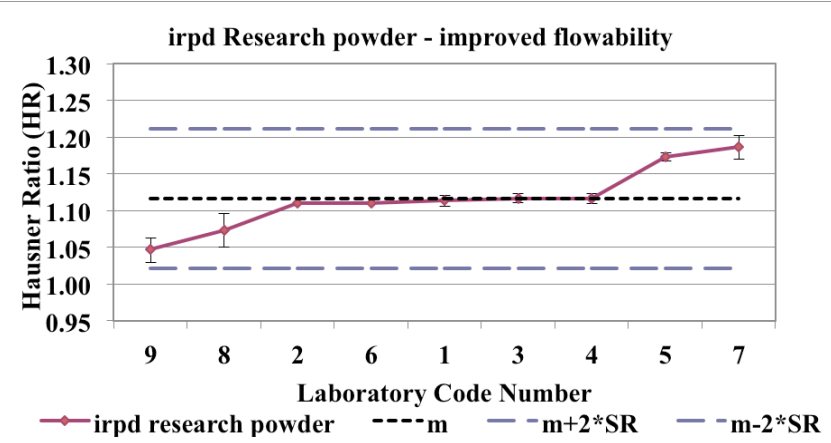

Figure 7. Summary of results of 9 labs for irpd research powder

In Figure 8 and 9 the results of Table 2 are summarized in an optical manner for better estimation. The mean values for HR for the 4 different materials are compared to each other and supplemented with $\mathrm{s}_{\mathrm{r}}$ (Figure 8 ) and $s_{R}$ (Figure 9). A clear difference of HR values with significant distinguised values is obvious.

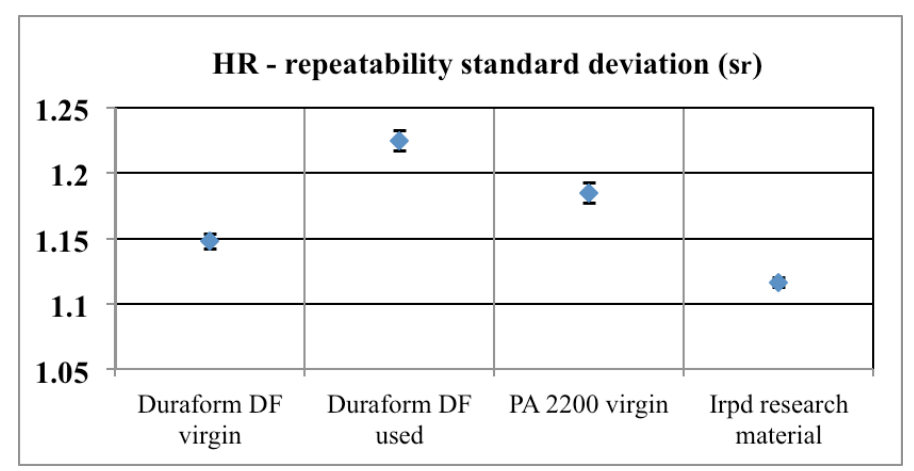

Figure 8. Materials of the round Robin in comparison with $\mathrm{s}_{\mathrm{r}}$

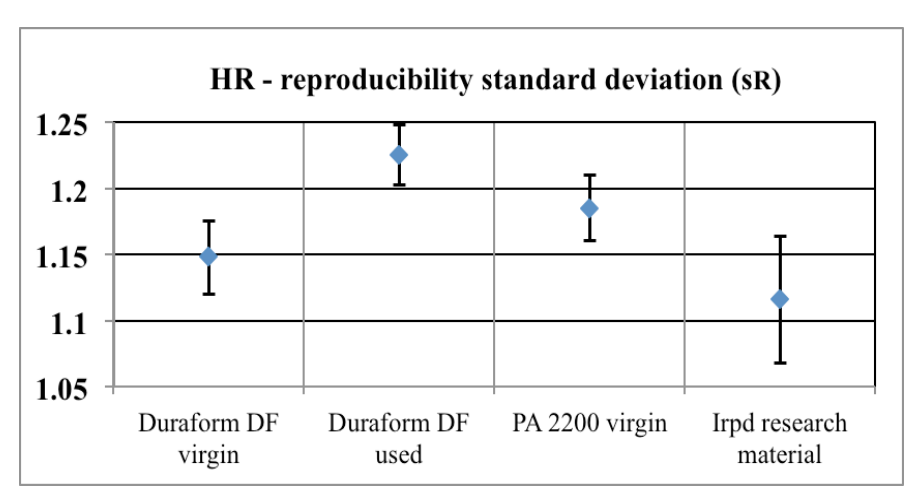

Figure 9. Materials of the round Robin in comparison with $\mathrm{S}_{\mathrm{R}}$

\subsection{Discussion of results}

From Table 2 and the optical depiction of HR values in Figure 8 and 9 it can be derived that the 4 materials can be easily distinguished regarding flowability with this effortless method. It is surprising that simply using a plastic measuring cylinder materials widely used in SLS business can be discriminated. Not only that used (aged) Duraform DF SLS powder has a significant higher HR-value (1.225) than all others, also virgin Duraform DF $(H R=1.148)$ and PA 2200 $(H R=1.185)$ can be statistically significant differntiated.

The results for 'Duraform DF - used' in comparison to 'DF- virgin' indicate that it might be possible to access the aging status of SLS powder by HR measurements. This could be a new approach to qualify SLS powders regarding usability prior to mixing for production. Today some service bureaus use MVR measurements for this purpose, but an alternative methode would be interesting, as MVR needs sophisticated equipment and has some restrictions especially for PA12 polymers.

\section{SUMMARY}

The present investigation describes a Round Robin Test comparison of 4 different SLS materials regarding powder flowability. The determination of 'Hausner Ratio (HR)' was performed from 9 differnet qualified SLS laboratories and users what means a sufficient number of data sets for significant conclusions. A robust statistical appraisal was used to achieve results for median (Hampel estimator), $\mathrm{s}_{\mathrm{r}}$ (standard deviation of repeatability) and $\mathrm{s}_{\mathrm{R}}$ (standard deviation of reproducibility).

With the obtained values it could be demonstrated that this simplyfied procedure of determining bulk and tap density is adequate to qualify and distinguish between different SLS powders. Thus, this simple method could be a promising approach to qualify PA12 SLS powders regarding their aging status and help SLS users to evaluate their powders prior to mixing. Further investigations with powders in different aged conditions are necessary and envisioned. 


\section{REFERENCES}

Affolter, S., et al. 2001 Macromol. Mater. Eng. 286(10), 605

Amado, A., et al. 2011. Advances in SLS Powder Characterization". Proceedings SFF Symposium, Austin, USA, 438-452

Barbosa-Canovas G.V. et al., 2005 Food Powders Kluwer Academic Press, New York, ISBN 0-306-47806-4, 55

Drummer, D., 2010, Development of a characterization approach for the sintering behavior of new thermoplastics for selective laser sintering, Physics Procedia (5) $533-542$

Ellison, S. L. R., Roesslein, M., Willams A. eds. 2000 EURACHEM/CITAC Guide, Second Edition, 7.

Gibson, I., et al. 2010 Additive Manufacturing Technologies, Springer Verlag GmbH, Berlin

Hopkinson, N., 2006 Rapid Manufacturing - An Industrial Revolution for the Digital Age, Wiley\&Sons, New York

Krantz, M., et al. 2009 Characterization of powder flow: Static and dynamic testing, Powder Technology, 196(1), pp. 239-245.

Kruth J. P., et al. 2007, Consolidation phenomena in laser and powder-bed based layerd manufacturing, CIRP Annals - Manufact Tech, 56(2), 730-759

Mandel, J., 1991 Chemometrics and Intelligent Laboratory Systems, (11) 109

Rietzel, D., et al. 2011 Polymer powders for selective laser sintering - production and characterization, Proc. 44th CIRP conference on Manufacturing Systems, Madison

Schmid, M., et al. 2011 "iCoPP - A New Polyolefin for Additive Manufacturing (SLS)", Proceedings of the International Conference on Additive Manufacturing, Session 7, Loughborough, U.K.

Wegner, A. \& Witt, G, 2012. „Betrachtung zur Pulvernutzungsdauer beim Laser-Sintern und Einfluss der Prozessführung auf die Entstehung von Ausschussbauteilen“. Proceedings of the Rapid Tech. Conference, Erfurt, Germany

Wendel B., et al. 2008. Additive Processing of polymers, Macromol Mater. Eng. 293, 799-809

Ziegelmeier S., et al. 2013, Characterizing the Bulk \& Flow Behavior of SLS Polymer Powders, Proceedings SFF Symposium, Austin (TX), USA 